Research article

\title{
Supracervical hysterectomy versus total abdominal hysterectomy: perceived effects on sexual function Jyot Saini ${ }^{1}$, Edward Kuczynski ${ }^{2}$, Herbert F Gretz III ${ }^{3}$ and E Scott Sills*4
}

Address: ${ }^{1}$ Department of Obstetrics and Gynecology, Indiana University Medical Center; Indianapolis, Indiana USA, ${ }^{2}$ Department of Obstetrics and Gynecology, New York University Medical Center; New York, New York USA, ${ }^{3}$ Division of Gynecologic Oncology, Department of Obstetrics and Gynecology, New York-Presbyterian Hospital, Weill Medical College of Cornell University; New York, New York USA and ${ }^{4}$ Division of Reproductive Endocrinology \& Infertility, Department of Obstetrics and Gynecology, Atlanta Medical Center; Atlanta, Georgia USA

E-mail: Jyot Saini - jsaini@iupui.edu; Edward Kuczynski - kuczye01@med.nyu.edu; Herbert F Gretz - herb.gretz@mssm.edu; E Scott Sills* - dr.sills@ivf.com

${ }^{*}$ Corresponding author

Published: 17 January 2002

Received: 17 September 2001

BMC Women's Health 2002, 2:I

Accepted: 17 January 2002

This article is available from: http://www.biomedcentral.com//472-6874/2/I

(C) 2002 Saini et al; licensee BioMed Central Ltd. Verbatim copying and redistribution of this article are permitted in any medium for any purpose, provided this notice is preserved along with the article's original URL.

\begin{abstract}
Background: Our investigation sought to compare changes in sexual function following supracervical hysterectomy $(\mathrm{SCH})$ and total abdominal hysterectomy $(\mathrm{TAH})$.

Methods: A retrospective chart review was performed to identify all patients who underwent supracervical hysterectomy or total abdominal hysterectomy at a tertiary care center. Patients who met criteria for participation were sent a one page confidential, anonymous questionnaire to assess sexual function experienced both pre- and postoperatively. A total of 69 patients in each group were eligible for participation. A multiple logistic regression model was used to analyze measured variables.
\end{abstract}

Results: Forty-eight percent $(n=33)$ of women undergoing a $\mathrm{SCH}$ returned the questionnaire, while $39 \%(n=27)$ of those undergoing a TAH chose to participate. There were no significant demographic differences between the two groups. Patients who underwent TAH reported worse postoperative sexual outcome than $\mathrm{SCH}$ patients with respect to intercourse frequency, orgasm frequency and overall sexual satisfaction $(P=0.0 \mathrm{I}, 0.03$, and 0.03 , respectively). Irrespective of type of hysterectomy, $35 \%$ of patients who underwent bilateral salpingoophorectomy (BSO) with hysterectomy experienced worse overall sexual satisfaction compared to $3 \%$ of patients who underwent hysterectomy alone $(P=0.02)$.

Conclusions: Our data suggest that TAH patients experienced worse postoperative sexual function than $\mathrm{SCH}$ patients with respect to intercourse frequency and overall sexual satisfaction. Irrespective of type of hysterectomy, patients who underwent bilateral salpingoophorectomy experienced worse overall sexual satisfaction.

\section{Introduction}

Hysterectomy is the most common gynecologic operation performed in the United States. It is estimated that by the age of 65,1 of 3 women will have undergone a hysterectomy $[1,2]$. Current practice in the United States strongly favors total abdominal hysterectomy (TAH) over suprac- 
ervical hysterectomy ( $\mathrm{SCH}$ ) for benign gynecologic disease. However, there has been a small but steady rise in the number of supracervical hysterectomies performed both regionally and nationally $[3,4]$. The reasons for this shift in hysterectomy type are multifactorial and poorly understood, but may reflect changing attitudes on the part of both patients and surgeons favoring less invasive operations. Potential advantages of SCH over TAH include decreased operative morbidity and reduced risk of urinary and sexual dysfunction [5-10]. Patient concerns about sexual functioning after hysterectomy may also play a role in the decision to undergo a supracervical hysterectomy versus total abdominal hysterectomy.

Various mechanisms have been proposed to explain why cervical conservation ( $\mathrm{SCH}$ ) may have a less detrimental effect on sexual function than TAH. Early pioneering work from the 1960's [11] described elevation of both cervix and uterus during the excitement and plateau phase followed by fundal uterine contractions progressively involving the lower uterine segment as orgasm developed. Cervical os dilatation occurred immediately afterwards, implicating a role for the cervix in the female sexual response.

Another theory postulates that the ability to achieve internal orgasm depends on the stimulation of nerve endings of the uterovaginal (cervical) plexus of Frankenhauser $[6,12]$. This plexus is a matrix of afferent nerve fibers intimately surrounding the cervix. Stimulation of the cervix may contribute to a pleasurable sensation, ultimately experienced as orgasm. Excision of the cervix that occurs during TAH necessarily results in the loss of a major portion of this plexus.

Studies examining sexual function after hysterectomy are contradictory and the controversy surrounding this topic is not new. Several investigators have reported a measurable decrease in sexual response after total abdominal hysterectomy [13-16] while others have found sexual functioning improved after hysterectomy $[17,18]$. Data regarding sexual function after an aggregation of all types of hysterectomy (TAH, $\mathrm{SCH}$, vaginal and laparoscopy assisted vaginal hysterectomy) are especially difficult to interpret [18]. One intuitive mechanism to account for improved sexual functioning post hysterectomy is the relief from dyspareunia caused by excision of uterine pathology (i.e., fibroids, menorrhagia).

Although there have been many studies exploring the general impact of total hysterectomy on sexual function, few have compared particular types of hysterectomy and their associated effect on subsequent sexual function. Indeed, only one investigator to date has explicitly examined the effect of type of hysterectomy (SCH versus TAH) on sexual function $[9,13]$. A statistically significant reduction in orgasm frequency among TAH patients when compared to $\mathrm{SCH}$ was reported in this population [13]. Ours is the first investigation in over a decade to offer a comparative analysis of sexual response as a function of hysterectomy type (SCH versus TAH).

\section{Methods}

A retrospective review was conducted of all patients who had undergone a TAH or SCH at The New York-Presbyterian Hospital Weill Medical College of Cornell University from January 1, 1994 to December 31, 1994. Patients with a diagnosis of cancer (gynecologic or non-gynecologic), psychiatric illness, neurologic disease, diabetes, chronic pelvic pain, endometriosis or a debilitating medical condition were excluded. Patients greater than age sixty and non-English speaking patients were excluded. Institutional review board approval was obtained before data collection.

A total of 333 hysterectomy patients were identified for the study period, and 160 of these did not meet criteria for participation as defined above. An additional 17 charts could not be located. This resulted in 156 patients eligible for inclusion in the study. Demographic data were obtained from the chart review of these patients and were entered into a computer database.

All hysterectomies were performed intrafascially using the clamp-cut-ligate method as described previously [19]. For SCH patients, the corpus was amputated below the level of the internal cervical os. The cervical stump was closed using interrupted No. 0 delayed absorbable suture (Polyglactin 910).

Table I: Outcome variables measured by questionnaire

\begin{tabular}{|c|c|}
\hline Sexual variable & Response choices \\
\hline libido (desire) & absent, moderate, strong \\
\hline frequency of intercourse (per month) & $0,1-3,4-6,7-9,>10$ \\
\hline dyspareunia (thrusting pain) & never, infrequently, fre- \\
\hline $\begin{array}{l}\text { porgasm frequency (ability to achieve } \\
\text { orgasm) }\end{array}$ & quently, always \\
\hline \multicolumn{2}{|l|}{ multiple orgasm } \\
\hline overall sexual satisfaction & worse, unchanged, better \\
\hline
\end{tabular}

Patients were sent a confidential questionnaire developed by a multidisciplinary team comprised of psychiatrists, statisticians, gynecologists, pathologists and a sexual therapist. It was pretested on a group of hysterectomy patients identified from a 1993 chart review at the same institution. Patient response and feedback from that survey re- 
sulted in the questionnaire being modified and condensed to one page. In its final form, the survey included 16 questions evaluating demographic data and measuring the following sexual variables: libido (desire), frequency of intercourse, dyspareunia, orgasm frequency, multiple orgasm frequency and overall sexual satisfaction. All questions were in a multiple-choice format although patients were allowed to add additional comments. In the questionnaire, patients were asked to describe their sexual function before and after their operation in absolute rather than relative terms in order to minimize recall bias (Ta- ble 1). Preoperative to postoperative change was then determined for each sexual variable and recorded as "better", "unchanged", or "worse". For example, a patient who preoperatively reported her frequency of intercourse (per month) as 1-3 and postoperatively as $4-6$ was identified as "better". Non-respondents were sent a second mailing approximately one month later. After this second questionnaire, no further attempt was made to contact patients. Patients who did not wish to participate in the study could so indicate, and they were not contacted further.

Table 2: Group characteristics

\begin{tabular}{|c|c|c|c|}
\hline & $\mathrm{SCH}(\mathrm{n}=33)$ & $\mathrm{TAH}(\mathrm{n}=27)$ & Significance \\
\hline Age (mean, +/- SD) & $45+/-5.0$ & $46+/-4.8$ & NS* \\
\hline \multicolumn{4}{|l|}{ Race } \\
\hline white & $21(64)$ & 16(59) & \\
\hline black & $6(18)$ & $6(22)$ & NS \\
\hline hispanic & $3(9)$ & $5(19)$ & \\
\hline asian & $3(9)$ & 0 & \\
\hline \multicolumn{4}{|l|}{ Marital status } \\
\hline married & $19(58)$ & $19(70)$ & \\
\hline single & $8(24)$ & $6(23)$ & NS \\
\hline divorced & $6(18)$ & $2(7)$ & \\
\hline $\begin{array}{l}\text { Length of stay (days) } \\
\text { (mean, +/- SD) }\end{array}$ & $4.3+/-1.5$ & $4.7+/-1.8$ & NS* \\
\hline \multicolumn{4}{|l|}{$($ mean, $+/-S D)$} \\
\hline \multicolumn{4}{|l|}{ Indications } \\
\hline leiomyoma & $26(79)$ & $16(60)$ & \\
\hline menometrorhagia & $3(9)$ & $6(22)$ & NS \\
\hline cyst & $3(9)$ & $3(I I)$ & \\
\hline other & I (3) & $2(7)$ & \\
\hline \multicolumn{4}{|l|}{ Incision type } \\
\hline pfannensteil & $25(76)$ & $23(85)$ & NS \\
\hline vertical & $8(24)$ & $4(15)$ & \\
\hline \multicolumn{4}{|c|}{ Previous abdominal surgery } \\
\hline yes & $17(52)$ & $10(37)$ & NS \\
\hline no & $16(48)$ & $17(63)$ & \\
\hline \multicolumn{4}{|l|}{ Parity } \\
\hline parous & $25(76)$ & $20(74)$ & NS \\
\hline nonparous & $8(14)$ & $7(16)$ & \\
\hline \multicolumn{4}{|l|}{ Same partner } \\
\hline yes & $27(84)$ & $19(79)$ & NS \\
\hline no & $5(16)$ & $5(2 I)$ & \\
\hline \multicolumn{4}{|l|}{ Oophorectomy } \\
\hline yes & $10(30)$ & $17(63)$ & $P<0.05$ \\
\hline no & $23(70)$ & $10(37)$ & \\
\hline \multicolumn{4}{|l|}{ Hormone replacement } \\
\hline yes & $12(36)$ & 16(59) & NS \\
\hline no & $21(64)$ & II (4I) & \\
\hline
\end{tabular}

Data are presented as $n(\%) ; N S=$ not significant; chi square test; NS* students $t$ test 
Data were analyzed using the JMP statistical package (version 3.2.2 SAS Institute; Carey, North Carolina USA). Chisquare or Student's- $t$ test was used to evaluate categorical or continuous demographic data and preoperative sexual function variables, as appropriate. A multiple logistic regression model was used to analyze independent predictor variables. Percent distributions were calculated for all variables. Statistical significance was defined as $P<0.05$.

\section{Results}

The patient-partitioning schema for the study population is shown in Figure 1. The proportion of responders was not significantly different between the two surgical subgroups (Table 2). Forty-eight percent $(\mathrm{n}=33)$ of women undergoing a $\mathrm{SCH}$ returned the questionnaire, while 39\% $(n=27)$ of those undergoing a TAR chose to participate. While all respondents answered the majority of questions, not all study patients answered every question. Nonetheless, there was no question in the survey answered by fewer than $74 \%$ of the respondents. The mean time (+SD) from surgery to questionnaire was 19.2 months $( \pm 3.4$ months) in the SCH group and 19.8 months $( \pm 3.9$ months) in the TAH group (range $=14-26$ months; $P>$ 0.05).

The demographic data obtained from the chart review and from the questionnaire are summarized in Table 2. The data illustrate that the two groups do not differ significantly except for oophorectomy status. Significantly more women underwent bilateral salpingoophorectomy (BSO) in the TAH group than in the SCH group (63 percent versus 30 percent, respectively; $P<0.05$ ). Since removal of the ovaries may have a deleterious effect on sexual function [20], the possible effects of oophorectomy on outcome measures were considered in the analysis. In addition, we considered the possible effects of hormone replacement therapy (HRT) of current users on sexual function, even though the two surgical groups showed no significant difference in reported use of HRT.

Outcome variables in which a pre-surgical subjective rating was elicited were evaluated and compared between the two groups (Table 3 ). In the TAH group, three women reported the absence of intercourse before surgery (versus no women in the $\mathrm{SCH}$ group), while in the $\mathrm{SCH}$ group proportionately more women reported intercourse $>6$ times/month. Although the possible effect of this finding on our ultimate outcomes was unclear, we included it as a possible confounder in our subsequent modeling process to insure that the results were not biased. We also added consideration of prior expectations regarding the likely effect of the surgery on sexual function, in an attempt to control for as many potential confounding variables as possible.

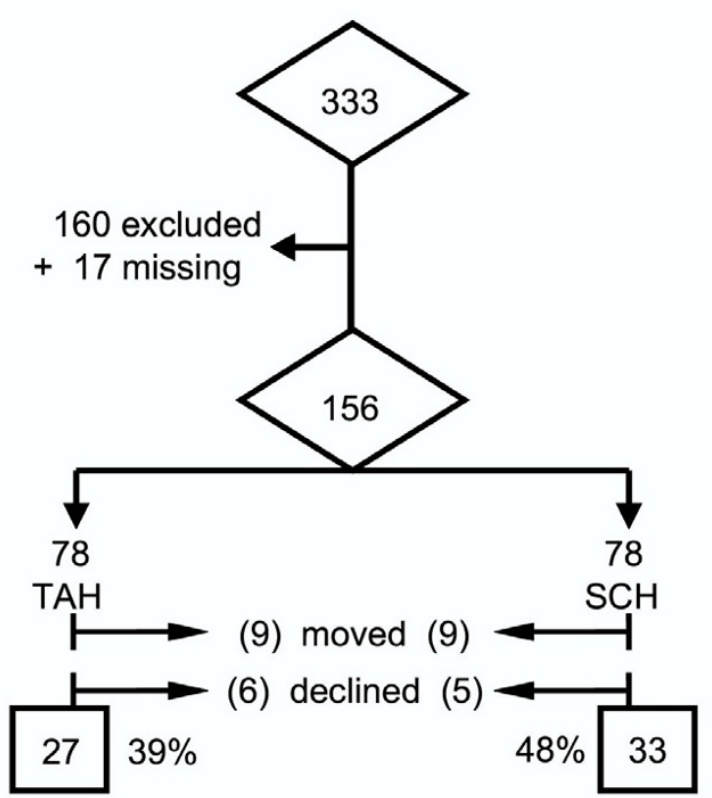

Figure I

The results of our initial analysis led to the construction of a multiple stepwise logistic regression model in which type of procedure, oophorectomy, use of HRT, frequency of intercourse prior to surgery, and preoperative expectations were used to predict the various sexual function outcome measures. Since our hypothesis centered on loss of sexual function, each of the outcome measures was categorized according to a binomial classification of function relative to pre-surgical status.

The relevant findings of this modeling procedure are summarized in Table 4. Changes in libido, dyspareunia, and multiple orgasm frequency were not predictable based upon any of our independent variables. However, intercourse frequency, orgasm frequency, and overall sexual satisfaction were all significantly related to type of procedure $(P=0.01,0.03$, and 0.03 , respectively). Regarding intercourse frequency, $42 \%(\mathrm{n}=10)$ of TAH patients experienced worse outcome compared with $15 \%(\mathrm{n}=5)$ of SCH patients. Forty-three percent $(n=9)$ of TAH patients experienced a decrease in the ability to achieve orgasm compared with $6 \%(n=2)$ of SCH patients. Overall sexual satisfaction was worse for $33 \%(n=8)$ of TAH patients compared with $6 \%(n=2)$ of SCH patients. Only for overall sexual satisfaction did oophorectomy add significant predictive value $(P=0.02)$. Thirty-five percent $(n=9)$ of patients who had a BSO with their hysterectomy had worse overall sexual satisfaction when compared to $3 \%$ (n $=1$ ) of patients who had hysterectomy only without BSO. 
Table 3: Baseline (preoperative) sexual function \& expectations

\begin{tabular}{|c|c|c|c|}
\hline & $\mathrm{SCH}$ & TAH & Significance \\
\hline \multicolumn{4}{|l|}{ Libido (desire) } \\
\hline absent & I (3) & $2(8)$ & \\
\hline moderate & $21(64)$ & $18(72)$ & NS \\
\hline strong & $11(33)$ & $5(20)$ & \\
\hline \multicolumn{4}{|l|}{ Dyspareunia } \\
\hline never & $19(58)$ & $8(35)$ & \\
\hline infrequently & $7(2 I)^{\prime}$ & $8(35)$ & NS \\
\hline frequently & $6(18)$ & $5(22)$ & \\
\hline always & I (3) & $2(9)$ & \\
\hline \multicolumn{4}{|l|}{ Multiple Orgasm } \\
\hline never & $8(26)$ & $4(17)$ & \\
\hline infrequently & $9(29)$ & $9(37)$ & NS \\
\hline frequently & $10(32)$ & $10(42)$ & \\
\hline always & $4(13)$ & I (4) & \\
\hline \multicolumn{4}{|c|}{ Intercourse frequency (per month) } \\
\hline 0 & 0 & $3(12)$ & \\
\hline $1-3$ & $11(33)$ & $4(16)$ & \\
\hline $4-6$ & $8(24)$ & $13(52)$ & $p<0.05$ \\
\hline 7-9 & $8(24)$ & $2(8)$ & \\
\hline$>10$ & $6(18)$ & $3(12)$ & \\
\hline \multicolumn{4}{|c|}{ Orgasm frequency } \\
\hline never & I (3) & 0 & \\
\hline infrequently & $5(16)$ & $4(17)$ & NS \\
\hline frequently & $18(58)$ & $12(52)$ & \\
\hline always & $7(23)$ & $7(30)$ & \\
\hline \multicolumn{4}{|l|}{ Expectations } \\
\hline worse & $13(39)$ & $5(22)$ & \\
\hline unchanged & $18(55)$ & $15(65)$ & NS \\
\hline better & $2(6)$ & $3(13)$ & \\
\hline
\end{tabular}

Data are presented as $\mathrm{n}(\%)$; Not all patients answered every question; NS = not significant, chi square test

Table 4: Sexual function results

\begin{tabular}{|c|c|c|c|c|c|c|c|}
\hline & \multicolumn{3}{|c|}{ Hysterectomy } & \multicolumn{2}{|c|}{ BSO } & \multicolumn{2}{|c|}{ HRT } \\
\hline & $\begin{array}{c}\mathrm{SCH} \\
(\mathrm{N}=33)\end{array}$ & $\begin{array}{c}\text { TAH } \\
(\mathrm{N}=27)\end{array}$ & $\begin{array}{c}\text { OR } \\
95 \% \mathrm{Cl}\end{array}$ & $\begin{array}{c}+ \\
(N=27)\end{array}$ & $\left(\begin{array}{c}- \\
(N=33)\end{array}\right.$ & $\begin{array}{c}+ \\
(\mathrm{N}=28)\end{array}$ & $\begin{array}{c}- \\
(N=32)\end{array}$ \\
\hline \multicolumn{8}{|l|}{ Libido } \\
\hline same/better & $27(87)$ & $17(68)$ & 3.2 & $16(64)$ & $28(90)$ & $19(70)$ & $26(87)$ \\
\hline worse & $4(13)$ & $8(32)$ & $(0.8-12.2)$ & $9(36)$ & $3(10)$ & $8(30)$ & $4(13)$ \\
\hline \multicolumn{8}{|l|}{ Dyspareunia } \\
\hline same/better & $30(91)$ & $18(90)$ & 1.1 & $22(92)$ & $27(90)$ & $24(92)$ & $25(89)$ \\
\hline worse & $3(9)$ & $2(10)$ & $(0.2-7.3)$ & $2(8)$ & $3(10)$ & $2(8)$ & $3(11)$ \\
\hline \multicolumn{8}{|l|}{ Multiple orgasm } \\
\hline same/better & $29(91)$ & $16(73)$ & 7.8 & $16(67)$ & $29(97)$ & $19(73)$ & $26(93)$ \\
\hline worse & $3(9)$ & $6(27)$ & $(1.5-40.9)$ & $8(33)$ & $\mathrm{I}(3)^{\prime}$ & $7(27)^{\prime}$ & $2(7)$ \\
\hline \multicolumn{8}{|c|}{ Intercourse frequency } \\
\hline same/better & $28(85)$ & $14(58)^{*}$ & 3.6 & $19(73)$ & $23(74)$ & $20(74)$ & $22(73)$ \\
\hline worse & $5(15)$ & $10(42)$ & $(0.8-16.5)$ & $7(27)^{\prime}$ & $8(26)$ & $7(26)^{\prime}$ & $8(27)$ \\
\hline
\end{tabular}


Table 4: Sexual function results (Continued)

\begin{tabular}{|c|c|c|c|c|c|c|c|}
\hline \multicolumn{8}{|l|}{ Orgasm frequency } \\
\hline same/better & $31(94)$ & $12(57)^{* *}$ & 11.6 & $\mid 4(6 \mid)$ & $29(94)$ & $17(68)$ & $26(90)$ \\
\hline worse & $2(6)$ & $9(43)$ & $(2.2-61.8)$ & $9(39)$ & $2(6)$ & $8(32)$ & $3(10)$ \\
\hline \multicolumn{8}{|c|}{ Overall sexual satisfication } \\
\hline same/better & $31(94)$ & $16(67)^{* * 1 * k}$ & 7.8 & $17(65)$ & $30(97)^{\dagger}$ & $20(74)$ & $27(90)$ \\
\hline worse & $2(6)$ & $8(33)$ & $(1.5-40.9)$ & $9(35)$ & $\mathrm{I}(3)$ & $7(26)$ & $3(10)$ \\
\hline
\end{tabular}

Data are presented as $n(\%)$ except OR $(95 \% \mathrm{Cl})$; Not all patients answered every question; ${ }^{*} \mathrm{p}=0.01,{ }^{* *} \mathrm{p}=0.03,{ }^{* * *} \mathrm{p}=0.03, \dagger_{\mathrm{p}}=0.02$, all others are not significant

With respect to HRT, there was no significant difference between sexual function of patients who were receiving hormone replacement and those who were not. Frequency of intercourse prior to surgery was not associated with postoperative change in any of the sexual variables analyzed $(P<0.05)$.

\section{Discussion}

The results presented here support a role for the cervix in the female sexual response. In particular, our finding of a statistically significant decrease in the ability to achieve orgasm among TAH patients when compared to $\mathrm{SCH}$ patients $(43 \%$ vs. $6 \%, P=0.03)$ is noteworthy. Our results support and expand upon the work by Kilkku [13] who reported a greater reduction in orgasm following TAH when compared to SCH $(P<0.05)$.

If patients derive less satisfaction from sexual intercourse by experiencing a reduction in their ability to achieve orgasm, then the frequency of intercourse might decrease. Indeed, in this study population both frequency of intercourse and overall sexual satisfaction were worse among TAH patients when compared to SCH patients. Previous investigators [14] found that $37 \%$ of patients after TAH/ BSO had a reduction in frequency of intercourse, similar to the $42 \%$ in our study group. The decline in overall sexual response after hysterectomy in our population was also consistent with results published by others $[15,16]$.

Dyspareunia was the only sexual variable where the results after surgery revealed no trend favoring $\mathrm{SCH}$. Nine percent $(n=3)$ of SCH patients and $10 \%(n=2)$ of TAH patients experienced worsening of dyspareunia after the operation. Sixty six percent of TAH patients and $42 \%$ of SCH patients experienced some degree of dyspareunia prior to surgery. Perhaps the dyspareunia was caused by intrauterine pathology, such as leiomyoma. Since uterine leiomyoma was the main indication for hysterectomy in $79 \%$ of SCH patients and $60 \%$ of TAH patients, hysterectomy could have resulted in a similar reduction of pain in the two groups. That hysterectomy ( $\mathrm{SCH}$ or TAH) is asso- ciated with improvement in dyspareunia supports the findings of others $[9,18,21,22]$.

Although the two surgical groups in this study are very similar, they do differ with respect to intercourse frequency and BSO status (Table 2 and 3). Because the independent variable in the statistical model was change in frequency of intercourse (postoperative frequency minus preoperative frequency) and not the magnitude of intercourse frequency, this disparity in the preoperative characteristics does not adversely impact our findings. Indeed, realizing that a sexual frequency of zero cannot become worse, this may have in fact biased the results in favor of the TAH cohort.

As demonstrated in the literature, the analysis of the relationship of BSO and postoperative sexual function is complex. Although one investigator reported no difference in libido between patients who underwent TAH and TAH/ BSO [15], our data are consistent with the findings of a more recent investigation [20] where BSO status did influence sexual outcome in the study population.

In accord with previous investigations $[14,15]$, we determined that HRT did not affect sexual outcome in any of the variables tested although the majority $(86 \%)$ of patients who were on HRT had undergone BSO. Perhaps this is because standard HRT may be insufficient to replace the full hormonal milieu produced by the ovary for some women, and other endogenous hormones may play a part in the female sexual response. For example, testosterone production continues even in the postmenopausal ovary, albeit at a markedly reduced rate [23]. A prospective, randomized study of TAH/BSO patients showed that those receiving combined testosterone and estrogen therapy had greater sexual desire than women receiving estrogen alone [24].

Menopausal status could have been directly determined from our questionnaire although it was found that the majority $(71 \%)$ of patients greater than age 45 in the study population underwent surgical menopause (BSO) 
and were taking HRT at the time of questionnaire completion.

\section{Conclusion}

In summary, we found that patients who underwent a TAH experienced worse sexual outcome than SCH patients with respect to frequency of intercourse, frequency of orgasm and overall sexual satisfaction. Our results suggest that type of hysterectomy does predict overall postoperative sexual satisfaction. Adding in the consideration of whether a BSO was performed significantly enhances this prediction. Prospective studies are needed to confirm these findings and determine the clinical impact that cervical and ovarian conservation may have for the patient.

\section{Competing interests}

None declared.

\section{References}

I. Wilcox LS, Koonin LM, Pokras R, Strauss LT, Zhisen X, Peterson HB: Hysterectomy in the United States, 1988-1990. Obstet Gynecol 1994, 83:549-55

2. Morley GW: Indications for hysterectomy. In: TeLinde's Operative Gynecology Updates. 1993, I:I-II

3. Sills ES, Saini J, Applegate MS, McGee M, Gretz HF 3d: Supracervical and total abdominal hysterectomy trends in New York State: 1990-1996. J Urban Health 1998, 75:903-10

4. Sills ES, Saini J, Steiner CA, McGee M, Gretz HF 3d: Abdominal hysterectomy practice patterns in the United States. Int J Gynecol Obstet 1998, 63:277-83

5. Munro MG: Supracervical hysterectomy: a time for reappraisal. Obstet Gynecol 1997, 89:133-9

6. Hasson HM: Cervical removal at hysterectomy for benign disease, risks and benefits. / Reprod Med 1993, 38:78I-90

7. Vara $P$, Kinnunen $O$ : Total vs. subtotal abdominal hysterectomy. Acta Obstet Gynecol Scand 1950, 3 I:4-43

8. Nathorst-Boos J, Fuchs T, von Schoultz BV: Consumer's attitude to hysterectomy, the experience of 678 women. Acta Obstet Gynecol Scand 1992, 71:230-4

9. Kilkku P: Supravaginal uterine amputation vs hysterectomy: effects on coital frequency and dyspareunia. Acta Obstet Gynecol Scand 1983, 62:14I-5

10. Kilkku P: Supravaginal uterine amputation versus hysterectomy with reference to subjective bladder symptoms and incontinence. Acta Obstet Gynecol Scand 1985, 64:375-9

II. Masters WH, Johnson VE: Human sexual response. Boston: Little, Brown, 1966111-26

12. Netter FH: The CIBA collection of medical illustrations, 1988, 2: 105

13. Kilkku P, Gronroos M, Hirvonen T, Rauramo L: Supravaginal uterine amputation vs. hyterectomy: effects on libido and orgasm. Acta Obstet Gynecol Scand 1983, 62:147-52

14. Dennerstein L, Wood C, Burrows GD: Sexual response following hysterectomy and oophorectomy. Obstet Gynecol 1977, 49:92-6

15. Utian WH: Effect of hysterectomy, oophorectomy and estrogen therapy on libido. Int J Gynaecol Obstet 1975, 13:97-100

16. Chakravarti S, Collins WP, Newton JR, Oram DH, Studd JW: Endocrine changes and symptomatology after oophorectomy in premenopausal women. Br J Obstet Gynaecol 1977, 84:769-75

17. Farrell SA, Kieser K: Sexuality after hysterectomy. Obstet Gynecol 2000, 95:1045-5|

18. Rhodes IC, Kjerulff KH, Langenberg PW, Guzinski GM: Hysterectomy and sexual functioning. JAMA 1999, 282:1934-4I

19. Thompson JD: Hysterectomy. In: TeLinde's Operative Gynecology 1993687-705

20. Nathorst-Boos J, von Schoultz B: Psychological reactions and sexual life after hysterectomy with and without oophorectomy. Gynecol Obstet Invest 1992, 34:97-101

21. Helstrom L, Lundberg PO, Sorbom D, Backstrom T: Sexuality after hysterectomy: a factor analysis of women's sexual lives be- fore and after subtotal hysterectomy. Obstet Gynecol 1993, 8I:357-62

22. Carlson KJ, Miller BA, Fowler FJ Jr: The Maine Women's Health Study, I: outcomes of hysterectomy. Obstet Gynecol 1994, 83:556-65

23. Chang J, Judd $\mathrm{H}$ : The ovary after the menopause. Clin Obstet Gynecol | 981, 24:|8|-9|

24. Sherwin BB, Gelfand MM, Brender W: Androgen enhances sexual motivation in females: a prospective, crossover study of sex steroid administration in the surgical menopause. Psychosom Med 1985, 47:339-5।
Publish with BioMed Central and every scientist can read your work free of charge

"BioMedcentral will be the most significant development for disseminating the results of biomedical research in our lifetime." Paul Nurse, Director-General, Imperial Cancer Research Fund

Publish with BMC and your research papers will be:

- available free of charge to the entire biomedical community

- peer reviewed and published immediately upon acceptance

- cited in PubMed and archived on PubMed Central

- yours - you keep the copyright

Submit your manuscript here:

http://www.biomedcentral.com/manuscript/
BioMedcentral.com editorial@biomedcentral.com 